\title{
Comunicação
}

[Communication]

\section{Prevalência de helicobactérias e alterações na mucosa gástrica de cães saudáveis}

\author{
[Prevalence of helicobacters and alterations in gastric mucosa of healthy dogs] \\ F.Q. Moutinho, A. Thomassian, M.J. Watanabe, S.M.C. Suzano, J.L. Sequeira \\ Faculdade de Medicina Veterinária e Zootecnia - UNESP \\ Caixa Postal 560 \\ 18618-000 - Botucatu, SP
}

Os microrganismos espiralados (helicobactérias) têm sido observados no estômago de cães há mais de um século (Happonen et al., 2000; Hwang et al., 2002). Porém, apenas após a descoberta do envolvimento do Helicobacter pylori (H. pylori), com a gênese de gastrites, úlceras pépticas, e neoplasias gástricas em seres humanos (Happonen et al., 1998; Simpson et al., 1999), é que se intensificaram os estudos sobre a incidência e a implicação clínica, da presença desses microrganismos gástricos em animais domésticos, especialmente em cães e gatos. Até o presente momento, contudo, não pode ser estabelecida uma associação positiva entre a presença desses microrganismos e alterações na mucosa gástrica desses indivíduos (Eaton et al., 1996). Os objetivos desta comunicação foram descrever a prevalência, a distribuição e densidade de colonização, de helicobactérias gástricas em cães saudáveis e caracterizar os aspectos microscópicos e macroscópicos da mucosa estomacal desses indivíduos.

Utilizaram-se $50^{*}$ cães selecionados, sem raça definida, adultos, machos e fêmeas, peso médio de $14 \pm 5,3 \mathrm{~kg}$, todos submetidos ao exame físico e a exames complementares incluindo: urinálise, hemograma, e determinações bioquímicas séricas das concentrações de uréia, creatinina, alanino aminotransferase (TGP), aspartato aminotransferase (TGO), fosfatase alcalina (FA), gama-glutamiltransferase (GGT), proteína sérica total (PT), albumina e cálcio, para confirmar o estado de higidez dos animais.

Recebido em 11 de outubro de 2006

Aceito em 4 de junho de 2007

E-mail: flaquaresma@hotmail.com

*Aprovado pela Câmara de Ética em Experimentação Animal (CEEA).
O protocolo de exame gastroscópico consistiu de jejum de 24 horas, aplicação de acepromazina (dose de $0,05 \mathrm{mg} / \mathrm{kg}$, pela via IM) como medicação pré-anestésica, butorfanol (dose de $0,1 \mathrm{mg} / \mathrm{kg}$, por via IM) para a analgesia, indução com tiopental (dose de $12,5 \mathrm{mg} / \mathrm{kg}$, pela via IV) e manutenção anestésica com halotano. Os cães foram mantidos em decúbito lateral esquerdo e para o exame gastroscópico foi utilizado um gastrofibroscópio flexível de $1 \mathrm{~m}$ x 7,9mm. Após cada procedimento endoscópico, a limpeza do fibroscópio foi efetuada com detergente enzimático e a desinfecção com glutaraldeído a $2 \%$ durante 30 minutos.

O exame macroscópico foi realizado conforme Silverstein e Tytgat (1998) analisando as regiões de antro, corpo e fundo gástrico, das quais foram obtidos fragmentos da mucosa para a detecção de helicobactérias e para a análise histológica. A determinação da prevalência das alterações macroscópicas baseou-se na presença de lesões em, pelo menos, uma das três regiões estudadas. $\mathrm{O}$ aspecto macroscópico foi classificado de acordo com os critérios da Tab. 1. Para a determinação da prevalência de helicobactérias foram realizados: o teste rápido da urease, o cultivo microbiológico e o exame histológico com as colorações de hematoxilina e eosina (HE) e de Giemsa, para confirmação. O exame histológico com a coloração de HE foi utilizado para a análise tecidual, para a classificação do tipo de infiltrado celular e para determinação da intensidade de colonização por helicobactérias, baseando-se na escala desenvolvida por Happonen et al. (1998). 
Tabela 1. Escala de graduação das alterações macroscópicas observadas na mucosa gástricas de cães

\begin{tabular}{cl}
\hline Grau & Tipo de alteração observada \\
\hline 0 & Normal, mucosa sem alterações \\
1 & Presença de edema \\
2 & Presença de eritema \\
3 & Presença de edema e eritema. \\
4 & Erosões únicas ou multifocais com ou \\
& sem edema e eritema \\
5 & Presença de úlceras, com ou sem \\
& erosões, eritema ou edema associados \\
\hline Moutinho (2004)
\end{tabular}

A prevalência de helicobactérias foi determinada pela análise percentual descritiva. $O$ teste de McNemar foi aplicado para determinar a discordância entre os exames diagnósticos. A densidade e intensidade de colonização da mucosa de cada região gástrica foram analisadas pelo teste $\mathrm{t}$ de Student. Para verificar a existência de associação entre o aspecto macroscópico e microscópico da mucosa, e a presença de helicobactérias, foi aplicado o teste de quiquadrado $\left(\chi^{2}\right)$.

A análise histológica revelou a presença dos microrganismos em 48 dos 50 animais analisados, o que reflete uma prevalência de $96 \%$. A prevalência de helicobactérias pela prova da urease foi de $100 \%$. O exame microbiológico foi realizado sem sucesso nas 300 amostras retiradas. $O$ teste de McNemar, não foi significativo $(p>0,05)$, ou seja, houve concordância de $96 \%$ entre os resultados do exame histológico e da prova da urease, confirmando a elevada prevalência de helicobactérias em cães saudáveis descrita na literatura (Hwang et al., 2002).

A prevalência de helicobactérias, nas distintas regiões gástricas, pelo método histológico foi de $26 \%$ (13/50) na região de antro, 62\% (31/50) na área de corpo e $82 \%$ (41/50) no fundo gástrico. A porcentagem de amostras positivas para a prova da urease na região de antro, foi de 22 , na região do corpo, de $88 \%$ na região de fundo de $90 \%$ $(45 / 50)$. A prevalência de helicobacétrias nas três regiões gástricas, analisadas pelas provas da urease e pela análise histológica, foi similar. Uma única exceção foi observada na região de corpo gástrico, onde o teste de McNemar foi significativo $\quad \mathrm{P}=0,006, \quad$ demonstrando concordância de apenas $62 \%$. Tal fato pode ser explicado pela distribuição esparsa das helicobactérias no estômago de cães, como já citado por Neiger e Simpson (2000), especialmente na região de corpo gástrico, que é a porção mais ampla do órgão.

As regiões de corpo e fundo gástricos apresentaram um padrão de colonização proporcional, porém, significativamente maior que o observado na região de antro estomacal. Apesar da grande diferença na prevalência de helicobactérias na porção de antro gástrico (menos infectada), o padrão de intensidade de colonização entre as três regiões foi similar, sendo observado em ambas o predomínio dos padrões discreto e moderado. Tal fato também foi relatado por Happonen et al. (1998), porém, com diferenças na intensidade de colonização, em que foi constatado, também nas três regiões estomacais, o predomínio dos padrões moderado e intenso.

A avaliação microscópica revelou a presença elevada de infiltrado celular em $64,7 \%$ das amostras gástricas, com predominância de infiltrado mononuclear, assim como observado por Happonen et al. (1998) e Hwang et al. (2002). Similar aos dados de literatura, a presença de alterações epiteliais foram mínimas (Happonen et al.,1998; Simpson et al., 1999; Hwang et al., 2002), revelando apenas 1,3\% de alterações. Apesar de a quantidade de infiltrado celular inflamatório ter sido elevada, clinicamente ela não foi significativa, pois essas características, são freqüentes, independentemente do estado de higidez do paciente (Yamazaki et al., 1998).

A associação entre a presença de infiltrado celular com a positividade de helicobactérias foi significativa para as regiões de antro e fundo estomacal, em relação ao exame histológico. Esse dado estatístico foi influenciado pela alta prevalência, tanto de helicobactérias como de células inflamatórias das regiões gástricas em questão. Assim, clinicamente, não podemos afirmar que exista uma relação positiva entre a presença de helicobactérias e a existência de alterações microscópicas em nosso experimento.

Simpson et al. (1999) constataram que o grau de infiltrado infamatório em animais infectados por Helicobacter felis é similar à quantidade 
observada em pacientes não infectados. Outro estudo, realizado por Flatland (2002), constatou que o padrão histológico compatível com gastrite crônica permanece inalterado, mesmo após o tratamento contra as helicobactérias, não havendo correlação entre a presença desses microorganismos e o padrão microscópico do estômago, como relatado em nosso experimento.

A presença de alterações macroscópicas foi de $58 \%$, o que representa 29 dos 50 animais avaliados. As diversidades dos aspectos observados estão descritos na Tab. 2. As alterações de menor gravidade representaram $65,3 \%$ do total de lesões, observadas em $38 \%$ dos animais. Essas alterações foram constituídas pela presença de edema (alterações de grau 1) e eritema (alterações de grau 2), ou associação entre elas (alterações de grau 3). As lesões erosivas (alterações de grau 4), consideradas de segunda gravidade, foram detectadas em apenas nove animais. Apenas um animal apresentou lesão ulcerosa (alteração de grau 5), na região do corpo gástrico.

A distribuição das alterações macroscópicas nas distintas regiões gástricas (Tab. 3), revelou maior prevalência de lesões erosivas (grau 4) na região de antro, com incidência significativa quando comparada com as das demais regiões. As lesões foram mais pronunciadas na convergência das pregas antrais, sendo mais freqüentes nos animais que apresentaram maior motilidade nesta região, o que pode ser justificado pelo intenso componente mecânico dessa porção estomacal, que se destina à trituração de partículas alimentares.
Tabela 2. Valores descritivos do padrão macroscópico encontrado nos 50 animais avaliados, com a distribuição total e percentual das alterações, considerando a alteração em apenas uma das regiões analisadas

\begin{tabular}{lccc}
\multicolumn{1}{c}{$\begin{array}{c}\text { Aspecto } \\
\text { macroscópico } \\
\text { da mucosa } \\
\text { gástrica }\end{array}$} & $\begin{array}{c}\text { Número } \\
\text { de } \\
\text { animais }\end{array}$ & $\begin{array}{c}\text { Percentual } \\
\text { total }\end{array}$ & $\begin{array}{c}\text { Valores } \\
\text { relativos }\end{array}$ \\
\hline $\begin{array}{l}\text { Mucosa normal } \\
\text { Grau 0 }\end{array}$ & 21 & $42 \%$ & $\begin{array}{c}(21 / 50) \\
42 \%\end{array}$ \\
Mucosa & & & $\begin{array}{c}(29 / 50) \\
\text { anormal }\end{array}$ \\
Grau 1 & 29 & $58 \%$ & $\begin{array}{c}58 \% \\
(3 / 29)\end{array}$ \\
Grau 2 & 3 & $6 \%$ & $\begin{array}{c}10,4 \% \\
(12 / 29)\end{array}$ \\
Grau 3 & 12 & $24 \%$ & $\begin{array}{c}41,4 \% \\
(4 / 29)\end{array}$ \\
Grau 4 & 4 & $8 \%$ & $\begin{array}{c}13,8 \% \\
(9 / 29) \\
31 \%\end{array}$ \\
Grau 5 & 9 & $18 \%$ & $\begin{array}{c}(1 / 29) \\
3,5 \%\end{array}$ \\
\hline
\end{tabular}

A pouca incidência de alterações gástricas graves (ulcerativas e erosivas) é perfeitamente condizente com os dados da literatura (Tams, 1999), sendo atribuída à ausência dos principais fatores potencialmente ulcerogênicos. As alterações de graus 1, 2 e 3 não são clinicamente significativas e ocorreram normalmente, em condições fisiológicas ou como conseqüência de eventos estressantes. Embora elevadas, as alterações macroscópicas observadas foram predominantemente discretas (lesões de grau 1, 2 e 3), portanto sem relevância clínica. Independentemente da região avaliada, não houve associação estatística entre a gravidade das alterações macroscópicas e a presença de helicobactérias.

Tabela 3. Distribuição total e percentual do aspecto da mucosa gástrica nas regiões de antro, corpo, e fundo estomacal e sua relação com a prevalência de helicobactérias, determinada pela análise histológica

\begin{tabular}{cccccccccc}
\hline & \multicolumn{3}{c}{ Antro } & \multicolumn{3}{c}{ Corpo } & \multicolumn{3}{c}{ Fundo } \\
& Total & Positivo & Negativo & Total & Positivo & Negativo & Total & Positivo & Negativo \\
& $\mathrm{N}(\%)$ & $\mathrm{N}(\%)$ & $\mathrm{N}(\%)$ & $\mathrm{N}(\%)$ & $\mathrm{N}(\%)$ & $\mathrm{N}(\%)$ & $\mathrm{N}(\%)$ & $\mathrm{N}(\%)$ & $\mathrm{N}(\%)$ \\
\hline Grau 0 & $27(54)$ & $9(18)$ & $18(36)$ & $32(64)$ & $19(38)$ & $13(26)$ & $38(76)$ & $29(58)$ & $9(18)$ \\
Grau 1 & 0 & 0 & 0 & $9(18)$ & $7(14)$ & $2(4)$ & $6(12)$ & $6(12)$ & 0 \\
Grau 2 & $13(26)$ & $2(4)$ & $11(22)$ & $4(8)$ & $1(2)$ & $3(6)$ & $2(4)$ & $2(4)$ & 0 \\
Grau 3 & $1(2)$ & $1(2)$ & 0 & $2(4)$ & $2(4)$ & 0 & $2(4)$ & $2(4)$ & 0 \\
Grau 4 & $9(18)$ & $1(2)$ & $8(16)$ & $2(4)$ & $2(4)$ & 0 & $2(4)$ & $2(4)$ & 0 \\
Grau 5 & 0 & 0 & 0 & $1(2)$ & 0 & $1(2)$ & 0 & 0 & 0 \\
Total & 50 & $13(26)$ & $37(74)$ & 50 & $31(62)$ & $19(38)$ & 50 & $41(82)$ & $9(18)$ \\
\hline
\end{tabular}

N: número total. 
Até o presente momento, a associação positiva entre a presença de helicobactérias com alterações macroscópicas e microscópicas significativas em cães só foi relatada em cães infectados experimentalmente com $H$. pylori e, ainda, com a utilização de cepas dotadas de virulência potencializada. Como o $H$. pylori não faz parte da microflora estomacal canina, essas alterações e a associação entre elas, não podem ser observadas em cães naturalmente infectados por helicobactérias (Rossi et al., 1999).

Palavras-chave: cão, Helicobacter, prevalência

\begin{abstract}
Prevalence, distribution and density of gastric helicobacter colonization were determined in 50 healthy dogs, characterizing the macroscopic and microcospic aspects of their mucosa. Helicobacter prevalence was $96 \%$, with greater distribution in the gastric fundus and body. Although the presence of macroscopic alterations was high (58\%), it was characterized as mild due to the predominance of less severe ones (65.5\%). High prevalence of mostly monoclear cell infriltate (64.7\%) was noted. Association between the presence of helicobacter and macro and microscopic alterations was not observed.
\end{abstract}

Keywords: dog, Helicobacter, prevalence

\section{REFERÊNCIAS BIBLIOGRÁFICAS}

EATON, K.A; DEWHIRST, F.E.; PASTER, B.J. Prevalence and varieties of Helicobacter species in dogs from random sources and pet dogs: Animal and public heath implications. J. Clin. Microbiol., v.34, p.3165-3170, 1996.

FLATLAND, B. Helicobacter infection in humans and animals. Compend. Cont. Educ. Pract. Vet., v.24, p.688-697, 2002.

HAPPONEN, I.; LINDEN, J.; SAARI S. et al. Detections and effects of helicobacters in healthy dogs and dogs with signs of gastritis. J. Am. Vet. Med. Assoc., v.213, p.1767-1774, 1998.

HAPPONEN, I.; LINDEM, J.; WESTERMARCK, E. Effect of triple therapy on eradication of canine gastric helicobacter and gastric disease. J. Small Anim. Pract., v.41, p.16, 2000.

HWANG, C.; HAN, H.; YOUN, H. Prevalence and clinical characterization of gastric Helicobacter species Infection of dogs and cats in Korea. J. Vet. Sci., v.3, p.123-133, 2002.

MOUTINHO, F.Q. Prevalência de lesões gástricas em cães e suas correlações com as concentrações séricas de gastrina e a presença de helicobactérias. 2004. 146f. Dissertação (Mestrado) - Faculdade de Medicina Veterinária e Zootecnia, Universidade Estadual Paulista, Botucatu.

NEIGER, R.; SIMPSON, K.W. Helicobacter infection in dogs and cats: facts and fiction. $J$. Vet. Intern. Med., v.14, p.125-133, 2000.

ROSSI, G.; ROSI, M.; VITALI, C. A conventional beagle dog model for acute and chronic infecction with Helicobacter pylori. Infect. Immun., v.67, p.3112-3120, 1999.

SILVERSTEIN, F.E; TYTGAT, G.N.J. O trato gastrointestinal normal. In:__. Endoscopia gastrintestinal. Rio de Janeiro: Revinter, 1998. p.1-26.

SIMPSON, K.W.; MCDONOUGH， P.L.; STRAUSS-AYALI, D. et al. Helicobacter felis Infection in dogs: effect on gastric structure and function. Vet. Pathol., v.36, p.237-248, 1999.

TAMS, T.R. Gastroscopy. In: TAMS, T.R. (Ed.). Small animal endoscopy. 2.ed. St. Louis: Mosby, 1999. p.97-172.

YAMASAKI, K.; SUEMATSU, H.; TAKAHASHI, T. Comparison of gastric lesions in dogs and cats with or without gastric spiral organisms. J. Am. Vet. Med. Assoc., v.212, p.529-533, 1998. 